\title{
Overview: Tropospheric profiling: state of the art and future challenges - introduction to the AMT special issue
}

\author{
D. Cimini ${ }^{1,2}$, V. Rizi ${ }^{2}$, P. Di Girolamo ${ }^{3}$, F. S. Marzano ${ }^{2,4}$, A. Macke ${ }^{5}$, G. Pappalardo ${ }^{1}$, and A. Richter ${ }^{6}$ \\ ${ }^{1}$ CNR-IMAA, C.da S.Loja, Tito Scalo, 85050, Potenza, Italy \\ ${ }^{2}$ CETEMPS, University of L'Aquila, Via Vetoio 1, 67100, L'Aquila, Italy \\ ${ }^{3}$ Scuola di Ingegneria, University of Basilicata, Via dell'Ateneo Lucano 10, 85100, Potenza, Italy \\ ${ }^{4}$ DIET, University of Rome, La Sapienza, Via Eudossiana 18, 00184, Rome, Italy \\ ${ }^{5}$ TROPOS, Leibniz Institute for Tropospheric Research, Permoserstraße 15, 04318 Leipzig, Germany \\ ${ }^{6}$ IUP, University of Bremen, Otto-Hahn-Allee 1, 28359 Bremen, Germany \\ Correspondence to: D. Cimini (domenico.cimini@imaa.cnr.it)
}

\begin{abstract}
This paper introduces the Atmospheric Measurement Techniques special issue on tropospheric profiling, which was conceived to host full papers presenting the results shown at the 9th International Symposium on Tropospheric Profiling (ISTP9). ISTP9 was held in L'Aquila (Italy) from 3 to 7 September 2012, bringing together 150 scientists representing of 28 countries and 3 continents. The tropospheric profiling special issue collects the highlights of ISTP9, reporting recent advances and future challenges in research and technology development.
\end{abstract}

\section{Introduction}

The Atmospheric Measurement Techniques (AMT) special issue on tropospheric profiling is the outcome of the 9th edition of the International Symposium on Tropospheric Profiling (ISTP9). ISTP9 was held in L'Aquila (Italy) from 3 to 7 September 2012, hosted by the Centre of Excellence for the Remote Sensing and Forecast of Severe Weather (CETEMPS) of University of L'Aquila (http://cetemps.aquila.infn.it/), in cooperation with the Institute of Methodologies for the Environmental Analysis of the National Research Council of Italy (CNR-IMAA, http://www.imaa.cnr.it), the European Space Agency (ESA, http://www.esa.int), and the office of European Cooperation in Science and Technology (COST, http://www.cost.eu). The main topics of the ISTP series include the profiling of atmospheric state parameters and constituents, the understanding of tropospheric processes, and the use of experimental data in atmospheric models. ISTP9 was organized in nine sequential sessions (see Table 1). For each session, keynote and relevant speakers were invited to set the stage for identifying the state of the art and discussing future directions of research and technology development. ISTP9 hosted 83 oral presentations and 140 extended abstracts. The abstracts and the proceedings of ISTP9 have been published by the ESA Conference Bureau and freely available online (Cimini et al., 2012a, b).

\section{The tropospheric profiling special issue}

The AMT special issue on tropospheric profiling was conceived to host full papers describing the state of the science presented at ISTP9. Twenty-one papers were initially submitted, of which 19 were published as discussion papers on AMTD (http://www.atmos-meas-tech-discuss.net/ special_issue 40.html), and the following 17 (in order of publication) were finally published on the AMT special issue (http://www.atmos-meas-tech.net/special_issue51.html).

Burton et al. (2013) present a comparison of aerosol classification products from the Cloud-Aerosol Lidar with Orthogonal Polarization (CALIOP) instrument on the CALIPSO satellite and the NASA Langley Research Center airborne High Spectral Resolution Lidar (HSRL-1). Based on 109 flights of HSRL-1 under the CALIOP orbit track, they provide insight into the performance of the CALIOP aerosol type algorithm and give recommendations aiming at its improvement.

Legain et al. (2013) propose a new system for highfrequency boundary layer profiling based upon conventional GPS radiosonde attached to a couple of inflated balloons. The new system allows two soundings - one ascending and one 
Table 1. List of ISTP9 sessions and corresponding chairs.

\begin{tabular}{|c|c|c|}
\hline Session & Topic & Chairs \\
\hline \multirow[t]{2}{*}{ A } & \multirow[t]{2}{*}{ Algorithms for Improved Parameter Retrievals } & I. Veselovskiy (PIC, Russia) \\
\hline & & V. Rizi (CETEMPS, U. L'Aquila, Italy) \\
\hline \multirow[t]{2}{*}{$\mathrm{B}$} & \multirow[t]{2}{*}{ Evaluation of Models and Data Assimilation } & J. Wilczak (NOAA, USA) \\
\hline & & T. Schwitalla (U. Hohenheim, Germany) \\
\hline \multirow[t]{4}{*}{$\mathrm{C}$} & \multirow[t]{4}{*}{ Aerosols, Clouds and Precipitation } & G. Stephens (NASA-JPL, USA) \\
\hline & & F. S. Marzano (CETEMPS, U. Rome, Italy) \\
\hline & & S. Crewell (U. Cologne, Germany) \\
\hline & & P. Di Girolamo (U. Basilicata, Italy) \\
\hline \multirow[t]{2}{*}{$\mathrm{D}$} & \multirow[t]{2}{*}{ Boundary Layer and Mesoscale Studies } & M. Hardesty (NOAA, USA) \\
\hline & & E. Batchvarova (NIMH, Bulgaria) \\
\hline \multirow[t]{2}{*}{$\mathrm{E}$} & \multirow[t]{2}{*}{ Validation, Instrument Synergies and Field Experiments } & A. Illingworth (U. Reading) \\
\hline & & H. Russchenberg (TUD, the Netherlands) \\
\hline \multirow[t]{2}{*}{$\mathrm{F}$} & \multirow[t]{2}{*}{ Thermodynamics, Turbulence and Radiation } & R. Goody (U. Harvard, USA) \\
\hline & & B. Demoz (Howard University, USA) \\
\hline \multirow[t]{2}{*}{ G } & \multirow[t]{2}{*}{ Networks, Satellites and Aircrafts } & G. Pappalardo (CNR-IMAA, Italy) \\
\hline & & T. Leblanc (NASA-JPL, USA) \\
\hline \multirow[t]{2}{*}{$\mathrm{H}$} & \multirow[t]{2}{*}{ New Instruments } & C. Serio (U. Basilicata, Italy) \\
\hline & & V. Chandrasekar (CSU, USA - FMI, Finland) \\
\hline \multirow[t]{2}{*}{ I } & \multirow[t]{2}{*}{ Water Vapor, Ozone and Trace Gases } & S. C. Reising (CSU, USA) \\
\hline & & T. Weckwerth (NCAR, USA) \\
\hline
\end{tabular}

descending - and a forecast-aided radiosonde recovery. The successful tests during two field experiments are presented (namely the Boundary Layer Late Afternoon and Sunset Turbulence (BLLAST) in 2011 and the Hydrological cycle in the Mediterranean Experiment (HyMeX) in 2012), showing a recovery rate of more than $80 \%$.

Bayat et al. (2013) report on the investigation of polarized sun-photometer measurements of aerosol optical depth, Ångström exponent, single-scattering albedo, and polarized phase function collected in Zanjan, northwest Iran. They found that the aerosol polarized phase function is strongly correlated with the Angström exponent, and that it also shows a moderate negative correlation with the aerosol optical depth and single-scattering albedo. Therefore, they conclude that the polarized phase is a key parameter to characterize the atmospheric particles of the region - a populated city in a semi-arid area of the earth's dust belt.

Adachi et al. (2013) present a method using volumetric C-band polarimetric radar data for very short-term forecasting of potentially hazardous convective clouds. The method is immune to the high reflectivity associated with hail as the effect of ice particles is removed based on polarimetric measurements. The results suggest that both the vertical maximum intensity of the rainfall rate and a high differential reflectivity extending above the freezing level, estimated from polarimetric measurements, are useful to identify potentially hazardous clouds.

Bock et al. (2013) report results from the field campaign conducted in September-October 2011 at Observatoire de Haute Provence in the framework of the Development of
Methodologies for Water Vapour Measurement (DEMEVAP) project. Two Raman lidars, a stellar spectrometer, a differential absorption spectrometer, a sun photometer, five GPS receivers and four types of radiosondes participated in the campaign, aiming at assessing humidity sounding techniques and establishing a reference system based on the combination of remote sensing sensors.

Güldner (2013) presents a retrieval analysis concerning a 22-channel microwave radiometer profiler operating at the Munich Airport during the "LuFo iPort VIS" campaign focusing on visibility forecast. The study aims at verifying the suitability of a numerical weather prediction (NWP) model for the calculation of model-based regression operators providing unbiased vertical profiles. The results of the study show that on the basis of NWP model data, available anytime from anywhere, the model-based regression method is capable of providing comparable results at a multitude of sites, offering auspicious conditions for automation and continuous updating.

Cimini et al. (2013) propose an innovative method for retrieving the mixing layer height (MLH) from ground-based microwave radiometer observations at multiple channels and elevation angles. The proposed method is shown to be able to follow both the diurnal cycle and the seasonal variability of MLH. Statistics with respect to reference lidar estimates show reasonable mean and root mean square differences and good correlation, demonstrating a new potential for atmospheric observation by ground-based microwave radiometry. 
Hurter and Maier (2013) discuss a collocation approach for reconstructing atmospheric wet refractivity profiles combining GPS zenith path delay, ground meteorological measurements, satellite radio occultation, and radiosonde measurements. They also derive relative humidity profiles combining the wet refractivity profiles with temperature profiles estimated with a ground-based V-band microwave radiometer, and validate both wet refractivity and relative humidity profiles against radiosonde profiles available at the same location. Results demonstrate that the collocation is capable of combining humidity-related data such that the resulting humidity profiles gain from complementary strengths of the various measurement methods.

Nemuc et al. (2013) present an 11-month-long analysis of multiwavelength depolarization Raman lidar measurements, discussing study cases for typical Saharan dust intrusion and biomass burning smoke. They conclude that calibrated depolarization measurements are critical to distinguishing between smoke-reach aerosol during the winter and dust-reach aerosol during the summer, as well as between elevated aerosol layers having different origins.

Lolli et al. (2013) report the results from testing a $0.355 \mu \mathrm{m}$ high spectral resolution backscatter Doppler lidar for atmospheric wind profiling. Using data from a field campaign conducted at the Haute Provence Observatory (France), the authors address the consistency of wind profile measurements made by different active remote sensors (lidars and a $72 \mathrm{MHz}$ radar) with balloon radio soundings, in light of the upcoming European Space Agency wind Doppler lidar mission (ADMAeolus), currently scheduled for launch in 2015.

Summa et al. (2013) consider three different methods for estimating the planetary boundary layer (PBL) height based on (i) radiosonde profiles, (ii) elastic and (iii) Raman lidar signals. Using data collected during the Convective and Orographically-induced Precipitation Study (COPS), they demonstrate that the latter approach is successfully applicable also in the afternoon-evening decaying phase of the PBL, when the effectiveness of the elastic lidar approach may be altered by the presence of the residual layer.

Federico (2013) reports the development of a novel threedimensional variational data assimilation system, tailored for the Regional Atmospheric Modeling System (RAMS; Cotton et al., 2003), to produce analyses for wind, temperature, relative humidity, and geopotential height. The system is applied to the real context of atmospheric profiling data over central Europe. Assimilated data are vertical soundings of wind, temperature, and relative humidity from radiosondes, and wind measurements of the European wind profiler network. The system performances are quantified by comparing the horizontal wind components at asynoptic times with measurements from the European wind profiler network, showing effective improvements at the short range (1-2 h).

Maruri et al. (2014) discuss the homogeneous sample volume assumption into the context of complex topography and extreme meteorological conditions. The homogeneity of the wind field over a boundary layer wind profiler radar located in complex terrain on the coast under different meteorological conditions is analyzed. The results reveal the importance of being aware of deviations in the homogeneity assumption, and we evaluate its effect on the final product. Quality indicators to be implemented at the product level are also proposed.

Pichelli et al. (2014) present a model analysis to reproduce the circulation in a urban area (Rome) with a high-resolution NWP model. The significant role of the urban surface forcing in the evolution of wind, temperature and water vapor content in the planetary boundary layer (PBL) is verified by comparing model results with observations coming from remote and in situ instruments (lidar, sodar, sonic anemometer and surface stations). The impact of different urban canopy models (UCMs) on the forecast is quantified. For the case study under analysis, the considered NWP model shows a tendency to overestimate vertical transmission of horizontal momentum from upper levels to low atmosphere, which is partially corrected by local PBL scheme coupled with an advanced UCMs.

Réchou et al. (2014) present an interesting approach to link measurements from UHF radar profiler to soil erosion on a volcanic island in a tropical zone (La Réunion, France). Measurements of reflectivity, vertical and horizontal wind are used, under suitable assumptions, to determine raindrop energy fluxes, which are essential for erosion caused by rainfall. One year of data is used to compute statistics of rain vertical profiles in different seasons and in case studies with typical conditions, such as summer deep convection, cold front, and winter depression embedded in trade winds. A simple relationship between the reflectivity factor and kinetic energy fluxes is found for each case study.

Montopoli et al. (2014) discuss the potentiality and drawbacks of X-band dual-polarization (DPX) radar measurements to estimate near-source volcanic ash cloud parameters. They present data acquired during the Grímsvötn (Iceland) volcanic eruptions in May 2011. A multi-source comparison is made in terms of total columnar concentration (TCC), encompassing a DPX, a C-band single-polarization radar and the satellite Special Sensor Microwave Imager/Sounder. Results show that high-spatial-resolution DPX radar data identify an evident volcanic plume signature, even though the interpretation of the polarimetric variables and the related retrievals is not always straightforward, likely due to ash and ice particle aggregate formation and radar signal depolarization induced by turbulence.

Maiello et al. (2014) report an assessment of Doppler weather radar (DWR) data assimilation into a NWP model for the prediction of heavy rainfall. The impact of the radar reflectivity and radial velocity on the assimilation into the Weather Research Forecasting (WRF) model is discussed. Several experiments are performed using different sets of initial conditions and a different assimilation strategy. In addition, three-dimensional variational sensitivity tests to outer loops are performed for each experiment to include the 
non-linearity in the observation operators. Results for a case study show that assimilation of DWR data, both reflectivity and radial velocity, has a positive impact on the prediction of heavy rainfall, and that warm-start strategies as well as outer-loop strategies lead to more accurate experiments.

\section{Concluding remarks}

A panel of seven experts summarized the conclusions of ISTP9 during the closing ceremony. The experts indicated that, in light of the unfavorable global economic situation, innovative research should expand the optimization of the existing observing resources and the synergy of different observing strategies. Aerosol-cloud-precipitation shall be investigated as a whole complex problem, as it is now possible with ground-based observations from well-equipped sites (Illingworth et al., 2013) as well as satellite observations from few-minute-spaced platforms (L'Ecuyer and Jiang, 2010). Stronger synergy between active and passive instrumentation shall be exploited for studying atmospheric processes and improving profiling accuracy. For example, the high vertical resolution of lidar combined with the large horizontal spatial coverage of radiometers from satellite can lead to a breakthrough in horizontal and vertical resolution of water vapor retrievals, as needed for forecasting of convective processes.

Tropospheric profiling has found new applications in the support of renewable (solar and wind) energy exploitation. This opened a new market for wind, aerosol, and cloud profiling, both from the modeling and observation points of view. The drawbacks of current operational sounding systems (namely the lack of vertical resolution of satellite and surface observations, and the sparse and infrequent distribution of radiosoundings) could be tackled by improving the utilization of existing technology for ground-based profiling. Common statistical methodologies are now applied in various atmospheric remote sensing and modeling fields. In particular, the Bayesian framework has become a reference for both physically based inversion algorithms and data assimilation into NWP models, greatly improving the links between the remote sensing and NWP communities. More emphasis shall be given to techniques enabling the identification of the contribution of individual instruments being assimilated to reducing forecast error. For example, the forecast sensitivity to observations (FSO) technique (Cardinali, 2009) has revealed that individual wind profilers make a big positive impact provided they were well maintained and located in a data-sparse area.

Integrated and long-term atmospheric observations are needed for weather, climate, and environment. Long-term sustainability means ensured resources for research infrastructures and guaranteed data access for users over decades to enable high-quality, curiosity-driven research. Stronger cooperation between scientists and instrument developers is also advisable; the lack of technical information associated with commercial non-disclosure agreements shall be overcome to ensure the best instrument characterization possible.

Indications for future research in the tropospheric profiling field come also from the contributions to the AMT special issue. Burton et al. (2013) suggested new features for future satellite lidar missions to improve the characterization of aerosol vertical distribution. Lolli et al. (2013) suggested the validation approach for the planned ESA Aeolus mission. Several authors (Burton et al., 2013; Bayat et al., 2013; Nemuc et al., 2013; Montopoli et al., 2014) pointed out that the information brought by multi-wavelength, dualpolarization observations should be further investigated by both experimental data and modeling. In order to consolidate demonstrative results, statistically significant data sets from long time periods (Pichelli et al., 2014) or from dedicated field experiments (Chen et al., 2013) deploying remote sensing observations should be considered. Results obtained considering pilot instrumentation should be extended to instrument networks, such as ground-based weather radars (Maiello et al., 2014) or microwave radiometers (Güldner, 2013). Several authors pointed out that instrument synergy should be better exploited to overcome intrinsic limitations and reduce the uncertainties of products, such as the PBL height (Cimini et al., 2013; Summa et al., 2013), atmospheric refractivity (Hurter and Maier, 2013), aerosol profiles (Marcos et al., 2013), and rainfall rates (Réchou et al., 2014). The availability of near-real-time data and smart information and communications technology tools is recognized as crucial for applications such as flight trajectory prediction (Legain et al., 2013), weather nowcasting (Hurter and Maier, 2013), and hazard early warning (Adachi et al., 2013). On the other hand, Bock et al. (2013) noted that long-term historical data sets may be reprocessed with new insight to infer by-products, such as integrated water vapor from astronomical spectrometers available starting at the beginning of the 20 th century. Finally, it was noted that automated procedures shall be developed for reducing the burden of routine data quality control (Güldner, 2013; Maruri et al., 2014) and for quantifying the impact of new data assimilation (Federico, 2013; Maiello et al., 2014), towards the optimization of the available resources. Experiments such as observing system and observing system simulation (OSE and OSSE, respectively) should be further exploited for quantifying the impact of remote sensing observations and guiding national weather services into next-generation mesoscale data assimilation.

In conclusion, ISTP9 and the associated AMT special issue have successfully represented an open forum for discussing the recent advances of tropospheric profiling research and technology development, providing a screenshot of the state of the art and future scientific challenges. 
Acknowledgements. The ISTP co-chairs are grateful to the institutional partners (CETEMPS, CNR-IMAA, COST, ESA), the technical sponsors (HIMET, ELDES, EURELETTRONICA ICAS, RADIOMETRICS, SELEX, RPG, LEOSPHERE, SCINTEC, CIMEL, THALES ALENIA), and the local authorities (Regione Abruzzo, Comune dell'Aquila, ANCE, AMA, Comando dei Vigili del Fuoco, Istituzione Sinfonica Abruzzese, Accademia delle Belle Arti, Conservatorio di Musica "A. Casella"), which provided resources and support for hosting ISTP9. The program and local organizing committees (available at: http://cetemps.aquila.infn.it/istp/proceedings/ hostandcommitees.html), as well as all the colleagues who helped review the manuscripts, are acknowledged for their support. The local staff is greatly acknowledged for their spontaneous and enthusiastic support (in alphabetical order: Eleonora Aruffo, Livio Bernardini, Fabio Biancofiore, Enzo Cerasani, Alberto Cirella, Valentina Colaiuda, Maura Coccia Colaiuta, Francesco De Angelis, Klaide De Sanctis, Fabio Di Sante, Sabrina Gentile, Marco Iarlori, Annalina Lombardi, Ida Maiello, Simona Marinangeli, Emanuela Pichelli, Paolo Ruggieri, Enrico Stagnini, Adriana Tiberi, Barbara Tomassetti, Paolo Tuccella). ISTP9 is dedicated to those who lost their lives and beloved ones in the 2009 L'Aquila earthquake. May peace be with them.

\section{References}

Adachi, A., Kobayashi, T., Yamauchi, H., and Onogi, S.: Detection of potentially hazardous convective clouds with a dualpolarized C-band radar, Atmos. Meas. Tech., 6, 2741-2760, doi:10.5194/amt-6-2741-2013, 2013.

Bayat, A., Khalesifard, H. R., and Masoumi, A.: Retrieval of aerosol single-scattering albedo and polarized phase function from polarized sun-photometer measurements for Zanjan's atmosphere, Atmos. Meas. Tech., 6, 2659-2669, doi:10.5194/amt-6-2659-2013, 2013.

Bock, O., Bosser, P., Bourcy, T., David, L., Goutail, F., Hoareau, C., Keckhut, P., Legain, D., Pazmino, A., Pelon, J., Pipis, K., Poujol, G., Sarkissian, A., Thom, C., Tournois, G., and Tzanos, D.: Accuracy assessment of water vapour measurements from in situ and remote sensing techniques during the DEMEVAP 2011 campaign at OHP, Atmos. Meas. Tech., 6, 2777-2802, doi:10.5194/amt-6-2777-2013, 2013.

Burton, S. P., Ferrare, R. A., Vaughan, M. A., Omar, A. H., Rogers, R. R., Hostetler, C. A., and Hair, J. W.: Aerosol classification from airborne HSRL and comparisons with the CALIPSO vertical feature mask, Atmos. Meas. Tech., 6, 13971412, doi:10.5194/amt-6-1397-2013, 2013.

Cardinali, C.: Monitoring the observation impact on the short-range forecast, Q. J. R. Meteorol. Soc., 135, 239-250, 2009.

Chen, H., Zhu, Y., Zhang, J., and Xuan, Y.: Vertical air motions derived from a descending radiosonde using a lightweight hard ball as the parachute, Atmos. Meas. Tech. Discuss., 6, 8107-8127, doi:10.5194/amtd-6-8107-2013, 2013.

Cimini, D., Di Girolamo, P., Marzano, F. S., and Rizi, V. (Eds.): Abstracts of the 9th International Symposium on Tropospheric Profiling, doi:10.12898/ISTP9abs, available at: http://cetemps. aquila.infn.it/istp/images/istp_program_final.pdf, 2012a.

Cimini, D., Di Girolamo, P., Marzano, F. S., and Rizi, V. (Eds.): Proceedings of the 9th International Symposium on Tropospheric Profiling ISBN/EAN: 978-90-815839-4-7,
doi:10.12898/ISTP9prc, available at: http://cetemps.aquila.infn. it/istp/proceedings/, 2012 b.

Cimini, D., De Angelis, F., Dupont, J.-C., Pal, S., and Haeffelin, M.: Mixing layer height retrievals by multichannel microwave radiometer observations, Atmos. Meas. Tech., 6, 2941-2951, doi:10.5194/amt-6-2941-2013, 2013.

Cotton, W. R., Pielke Sr., R. A., Walko, R. L., Liston, G. E., Tremback, C. J., Jiang, H., McAnelly, R. L., Harrington, J. Y., Nicholls, M. E., Carrio, G. G., and McFadden, J. P.: RAMS 2001: Current status and future directions, Meteor. Atmos., Phys., 82, 5-29, 2003.

Federico, S.: Implementation of a 3D-Var system for atmospheric profiling data assimilation into the RAMS model: initial results, Atmos. Meas. Tech., 6, 3563-3576, doi:10.5194/amt-6-35632013, 2013.

Güldner, J.: A model-based approach to adjust microwave observations for operational applications: results of a campaign at $\mathrm{Mu}-$ nich Airport in winter 2011/2012, Atmos. Meas. Tech., 6, 2879 2891, doi:10.5194/amt-6-2879-2013, 2013.

Hurter, F. and Maier, O.: Tropospheric profiles of wet refractivity and humidity from the combination of remote sensing data sets and measurements on the ground, Atmos. Meas. Tech., 6, 30833098, doi:10.5194/amt-6-3083-2013, 2013.

Illingworth A. J., Ruffieux, D., Cimini, D., Löhnert, U., Haeffelin, M., and Lehmann, V. (Eds.): COST Action ES0702 EG-CLIMET - Final Report, doi:10.12898/ES0702FR, 2013.

L'Ecuyer, T. S. and Jiang, J. H.: Touring the atmosphere aboard the A-Train, Physics Today, 63, 36-41, 2010.

Legain, D., Bousquet, O., Douffet, T., Tzanos, D., Moulin, E., Barrie, J., and Renard, J.-B.: High-frequency boundary layer profiling with reusable radiosondes, Atmos. Meas. Tech., 6, 21952205, doi:10.5194/amt-6-2195-2013, 2013.

Lolli, S., Delaval, A., Loth, C., Garnier, A., and Flamant, P. H.: 0.355-micrometer direct detection wind lidar under testing during a field campaign in consideration of ESA's ADM-Aeolus mission, Atmos. Meas. Tech., 6, 3349-3358, doi:10.5194/amt6-3349-2013, 2013.

Maiello, I., Ferretti, R., Gentile, S., Montopoli, M., Picciotti, E., Marzano, F. S., and Faccani, C.: Impact of radar data assimilation for the simulation of a heavy rainfall case in central Italy using WRF-3DVAR, Atmos. Meas. Tech., 7, 2919-2935, doi:10.5194/amt-7-2919-2014, 2014.

Marcos, C., Pedrós, R., Gómez-Amo, J. L., Sicard, M., Utrillas, M. P., Muñoz, C., Comerón, A., and Martinez-Lozano, J. A.: Daytime aerosol extinction profiles from the combination of CALIOP profiles and AERONET products, Atmos. Meas. Tech. Discuss., 6, 3983-4038, doi:10.5194/amtd-6-3983-2013, 2013.

Maruri, M., Romo, J. A., and Gomez, L.: Aspects of quality control of wind profiler measurements in complex topography, Atmos. Meas. Tech., 7, 135-148, doi:10.5194/amt-7-135-2014, 2014.

Montopoli, M., Vulpiani, G., Cimini, D., Picciotti, E., and Marzano, F. S.: Interpretation of observed microwave signatures from ground dual polarization radar and space multi-frequency radiometer for the 2011 Grímsvötn volcanic eruption, Atmos. Meas. Tech., 7, 537-552, doi:10.5194/amt-7-537-2014, 2014.

Nemuc, A., Vasilescu, J., Talianu, C., Belegante, L., and Nicolae, D.: Assessment of aerosol's mass concentrations from measured linear particle depolarization ratio (vertically resolved) and sim- 
ulations, Atmos. Meas. Tech., 6, 3243-3255, doi:10.5194/amt-63243-2013, 2013.

Pichelli, E., Ferretti, R., Cacciani, M., Siani, A. M., Ciardini, V., and Di Iorio, T.: The role of urban boundary layer investigated with high-resolution models and ground-based observations in Rome area: a step towards understanding parameterization potentialities, Atmos. Meas. Tech., 7, 315-332, doi:10.5194/amt-7-3152014, 2014.
Réchou, A., Narayana Rao, T., Bousquet, O., Plu, M., and Decoupes, R.: Properties of rainfall in a tropical volcanic island deduced from UHF wind profiler measurements, Atmos. Meas. Tech., 7, 409-418, doi:10.5194/amt-7-409-2014, 2014.

Summa, D., Di Girolamo, P., Stelitano, D., and Cacciani, M.: Characterization of the planetary boundary layer height and structure by Raman lidar: comparison of different approaches, Atmos. Meas. Tech., 6, 3515-3525, doi:10.5194/amt-6-3515-2013, 2013. 